\title{
Keeping up with studies on covid-19: systematic search strategies and resources
}

\author{
Farhad Shokraneh information scientist \\ Cochrane Schizophrenia Group, Institute of Mental Health, University of Nottingham, Nottingham NG7 2TU, UK
}

The reason I write this letter is to take a small step towards helping readers with evidence based decision making by keeping them up to date with the rapidly growing number of covid-19 studies in PubMed and other resources. ${ }^{1}$ Many studies are not going to be visible in PubMed or Embase in the next few months because of indexing and content policy in bibliographic databases that avoids indexing preprint and unpublished studies, including registered clinical trials.

PubMed for recent published literature on covid-19

Live strategy and results in current PubMed: tinyurl.com/ waj $7 \mathrm{hmj}$

Live strategy and results in future PubMed: tinyurl.com/ uwbsvo2

medRxiv and bioRxiv for unpublished studies on covid-19 connect.medrxiv.org/relate/content/181

ClinicalTrials.Gov for clinical trials on covid-19

Live strategy and results: tinyurl.com/t9vwzfo

Google Scholar for published and unpublished literature on covid-19

Live strategy and results: tinyurl.com/spj6oox
Evidence for Policy and Practice Information and Co-ordinating Centre: covid-19: living map of the evidence tinyurl.com/rw5ym7x

Cochrane resources on coronavirus (covid-19) www.cochranelibrary.com/covid-19

Oxford covid-19 evidence service www.cebm.net/covid-19

NICE rapid guideline and summaries on covid-19 www.nice.org.uk/covid-19

WHO coronavirus disease (covid-19) pandemic www.who.int/emergencies/diseases/novel-coronavirus-2019

Competing interests: None declared.

Godlee F. Covid-19: weathering the storm. Editor's choice. BMJ 2020;368:m119910.1136/bmj.m1199.

Published by the BMJ Publishing Group Limited. For permission to use (where not already granted under a licence) please go to http://group.bmj.com/group/rights-licensing/ permissions 